\title{
THE EVOLUTION-CREATION CONTROVERSY
}

Perspectives on Religion, Philosophy, Science and Education

\section{A HANDBOOK}

Proceedings of a Symposium Convened by

Robert A. Gastaldo and William F. Tanner
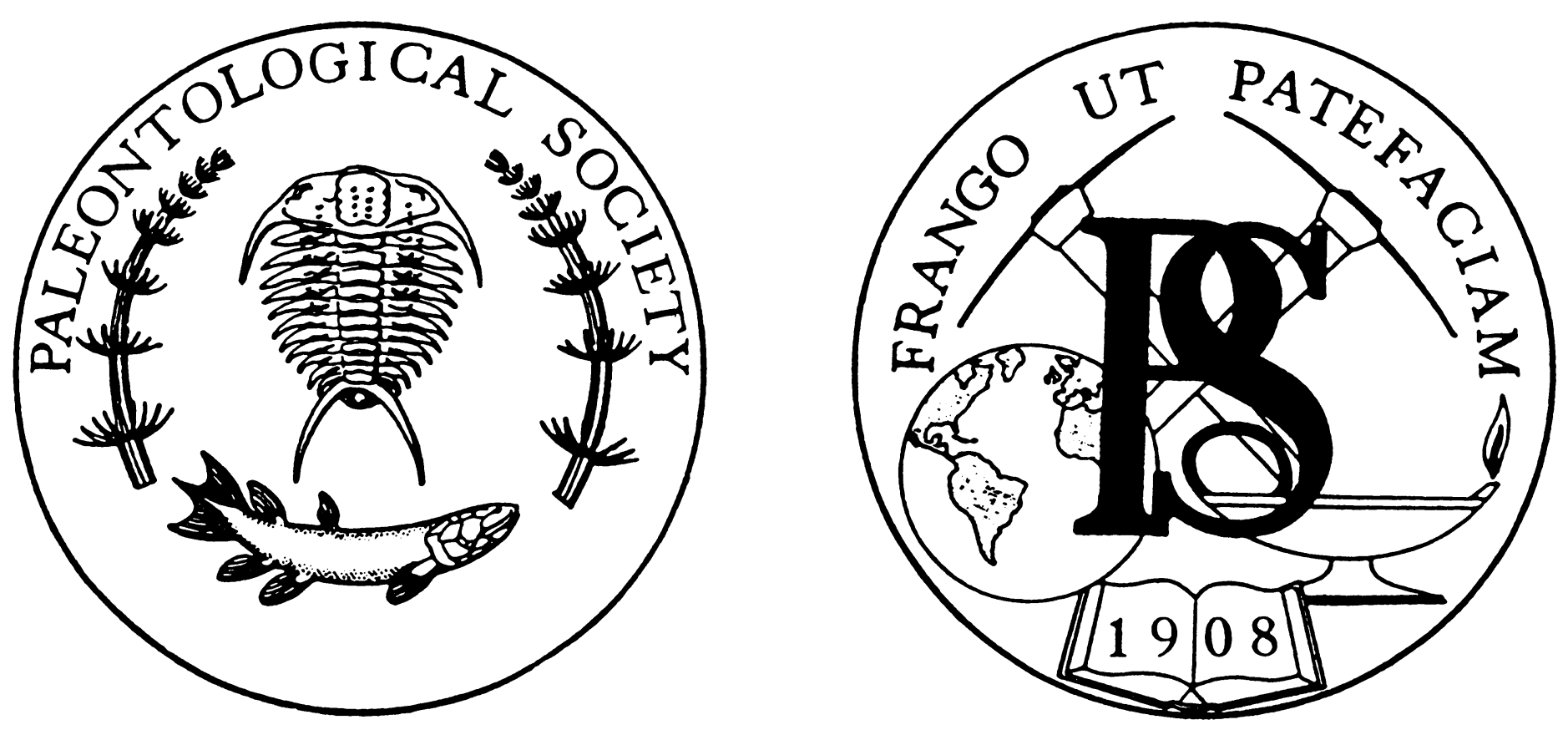

THE PALEONTOLOGICAL SOCIETY

SPECIAL PUBLICATION No. 1

1984

Kenneth R. Walker

Editor

Reprinted 1996 


\section{THE EVOLUTION-CREATION CONTROVERSY}

Perspectives on Religion, Philosophy, Science and Education

\section{A HANDBOOK}

Proceedings of a Symposium Convened by

Robert A. Gastaldo and William F. Tanner
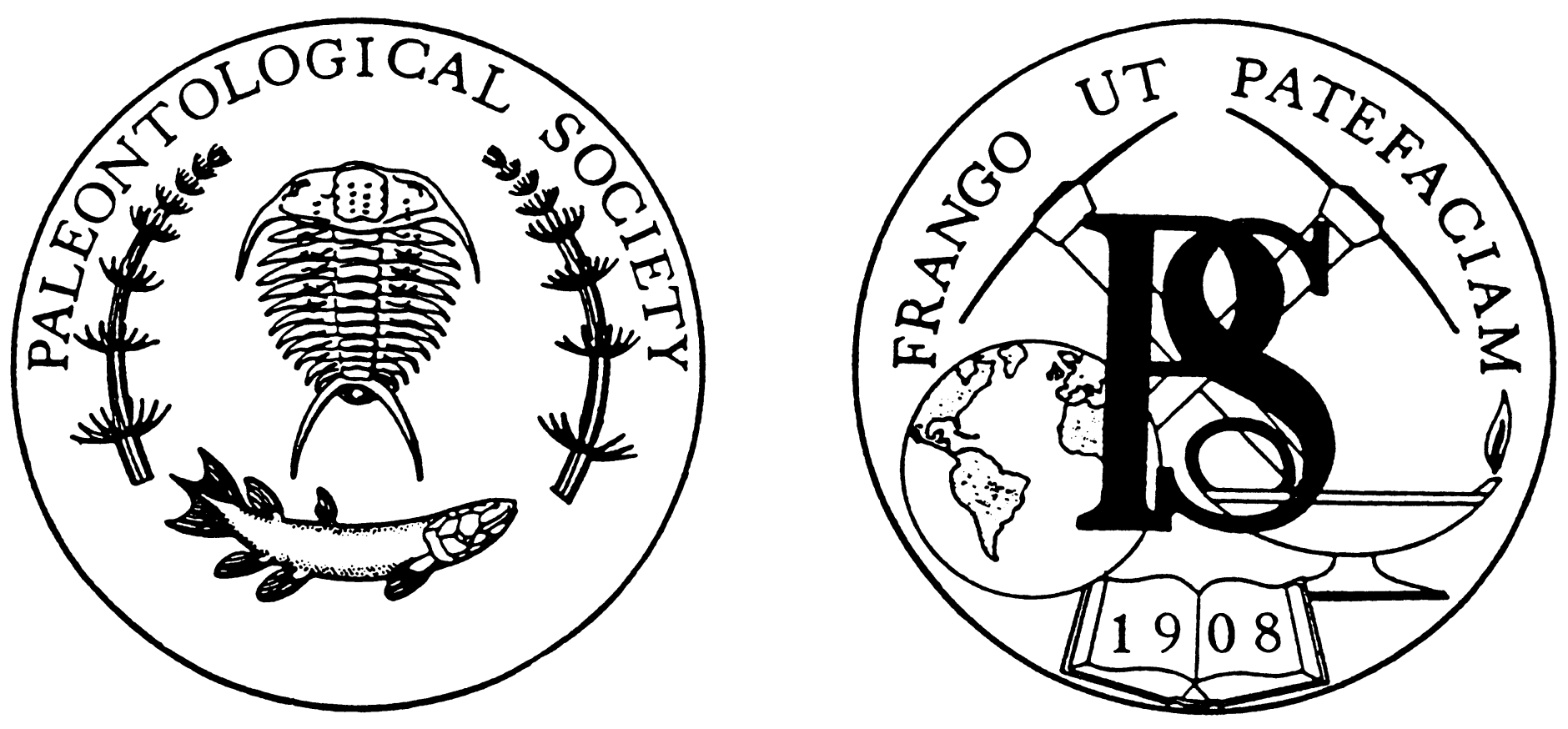

THE PALEONTOLOGICAL SOCIETY

SPECIAL PUBLICATION No. 1

1984

Kenneth R. Walker

Editor

Reprinted 1996 
Paleontological Society Special Publication 1

\section{ISBN 0-931377-00-5}

Printed at The University of Tennessee, Knoxville publication EO1-1040-005-94

The University of Tennessee, Knoxville, does not discriminate on the basis of race, sex, color, religion, national origin, age, handicap or veteran status in provision of educational opportunities or employment benefits.

UTK does not discriminate on the basis of sex or handicap in the educational programs and activities which it operates, pursuant to requirements of Title IX of the Educational Amendments of 1972, Public Law 92-318; and section 504 of the Rehabilitation Act of 1973, Public Law 93-112; respectively. This policy extends both to employment and admission to the University.

Inquiries concerning Title IX and Section 504 should be directed to the Director of Affirmative Action; 403-B Andy Holt Tower, The University of Tennessee, Knoxville, Tennessee 37996-0144; (615) 974-2498. Charges of violation of the above policy should be directed to the Office of the Director of Affirmative Action. 


\section{CONTERTS}

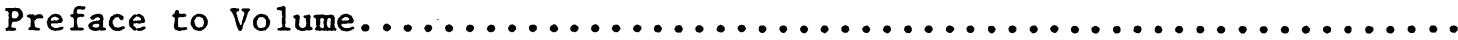

Is There Scientific Method In Creationist Madness?................

by D. R. Schwimner

Some Historical and Philosophical Perspectives on Science, Evolution,

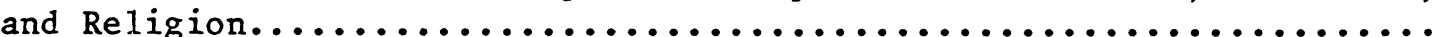
by L. D. Campbe11

Partial Catastrophism and Pick \& Choose Empiricism: The Science

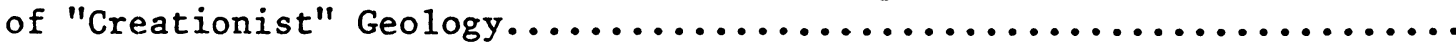
by W. J. Frazier

The Consistency of Radiometric Dating in the Geological Record....... by J. R. Osmond

Geological Age Determinations by Non-radiometer Methods. by J. B. Cowart

Heterochrony and the Problem of Missing Links in Evolutionary

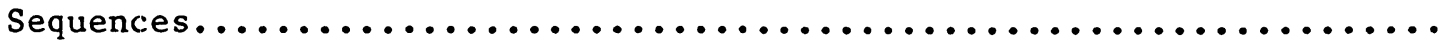

by T. W. Broadhead and J. A. Waters

A Case Against Pelagochthony: The Untenability of Carboniferous

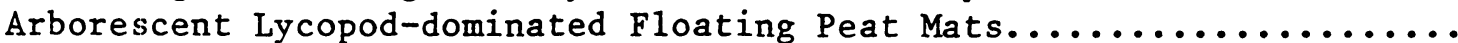
by R. A. Gastaldo

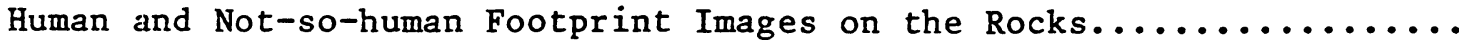
by W. F. Tanner

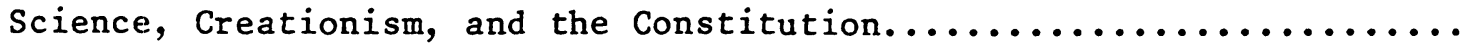
by D. B. Mckown

Scientific Validity of Proposed Public Education Materials for Balanced Treatment of Creationism and Evolution in Elementary

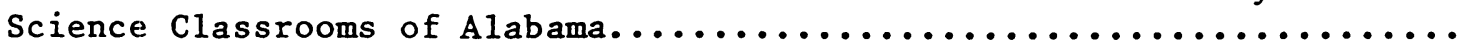
by S. Brande 